\title{
Different goals, different pathways to success: Performance-approach goals as direct and mastery-approach goals as indirect predictors of grades in mathematics
}

\author{
Athanasios Mouratidis $^{\mathrm{a}, *}$, Aikaterini Michou ${ }^{\mathrm{b}}$, Ayşe Nur Demircioğlu ${ }^{\mathrm{c}}$, Melike Sayil ${ }^{\mathrm{d}}$ \\ ${ }^{a}$ Department of Psychology, TED University, Turkey \\ b Graduate School of Education, Bilkent University, Turkey \\ ${ }^{\mathrm{c}}$ Department of Psychology, Ankara University, Turkey \\ ${ }^{\mathrm{d}}$ Department of Psychology, TED University, Ankara, Turkey
}

\section{A R T I C L E I N F O}

\section{Keywords:}

Achievement goals

Learning environment

Academic performance

Challenge seeking

Adolescence

Mathematics

\begin{abstract}
A B S T R A C T
In this study, we aimed to investigate the different routes through which perceived goal structures, and in turn mastery-approach and performance-approach goals in mathematics, predict subsequent academic performance. Path analyses with a sample of Turkish adolescents $\left(N=369 ; 49.1 \%\right.$ males; $M_{\text {age }}=16.67$ years, $\left.S D=1.85\right)$ revealed two distinct paths. After controlling for mid-year grades, we found perceived mastery goal structures to relate (positively) to mastery-approach goals, which in turn positively predicted end-year grades through challenge seeking. In contrast, perceived performance goal structures related positively to both performanceapproach and performance-avoidance goals with the former directly predicting higher end-year grades, and the latter being related negatively to challenge seeking. These findings imply that there may exist different paths that can predict academic performance.
\end{abstract}

\section{Introduction}

Achievement goal theorists have been debating for over a decade about whether performance-approach goals (i.e., goals that aim at outperforming others) constitute a maladaptive form of motivation and hence whether it should be totally discouraged by teachers and parents (Harackiewicz, Barron, Pintrich, Elliot, \& Thrash, 2002; Midgley, Kaplan, \& Middleton, 2001). This is because performance-approach goals, as compared to mastery-approach goals (i.e., goals focusing on attaining mastery and learning), can become a double-edged sword as the highly likely costs (such as challenge avoidance) that they inherently carry outweigh the few benefits that they might bring (e.g., higher grades) (Brophy, 2005). Although mastery-approach goals are considered more adaptive than performance-approach goals (Hulleman \& Senko, 2010; Midgley et al., 2001), it should be admitted however that performance-approach goals may become attractive for many students, teachers, and parents, namely because they are positively associated with a valuable outcome: Higher grades.

Indeed, prior research has pointed out that performance-approach goals can more reliably predict academic performance than masteryapproach goals (Hulleman, Schrager, Bodmann, \& Harackiewicz, 2010). Yet, as Senko, Hulleman, and Harackiewicz (2011) proposed, mastery- approach goals may also predict higher academic performance, yet indirectly through some intervening mechanisms. Remarkably, although this suggestion seems to resolve several issues regarding whether mastery-approach goals can also predict higher performance, it has received little attention. This is unfortunate because if mastery-approach goals are indeed conducive of higher grades, through different channels, then their utility value can be further underscored.

Showing thus that mastery-approach goals can also predict academic performance, may render performance-approach goals even less attractive among teachers, parents, or education-policy makers who might favor them. In that way, students may be further discouraged to endorse performance-approach goals and thus they may be further protected from their side effects. In our study, we aimed to shed light on this issue. In particular, we aimed to investigate whether mastery-approach goals can also predict, next to performance-approach goals, higher grades, yet indirectly through challenge seeking. We opted for challenge seeking as it is considered a key marker of adaptive achievement striving (Dweck, 1986) and an index of students' cognitive, affective, and motivational growth (Meyer, Turner, \& Spencer, 1997). By showing that mastery-approach goals may also predict higher grades at school, we aimed to further highlight the usefulness of mastery-approach goals as the safe route through which students can

\footnotetext{
* Corresponding author at: Department of Psychology, TED University, Ziya Gokalp, 48, 06420 Ankara, Turkey.

E-mail address: athanasiosmouratidis@tedu.edu.tr (A. Mouratidis).
} 
pursue their academic goals, including higher grades.

\subsection{Achievement goals and academic performance}

Broadly speaking, achievement goals have been defined as the reasons for which people strive for success in achievement settings (Ames \& Archer, 1988; Dweck \& Leggett, 1988; Nicholls, 1984). The most commonly agreed conceptualization of achievement goals distinguishes them depending on how people define and valence (i.e., appraise) competence (Elliot \& McGregor, 2001). Based on that definition, three types of achievement goals seem especially relevant in the educational contexts; these are (a) mastery-approach goals when competence is defined with absolute or self-referenced criteria and is valenced positively; (b) performance-approach goals when competence is defined with normative criteria and is valenced positively; and (c) performanceavoidance goals when competence is defined with normative criteria and is valenced negatively. A student who strives to comprehend the subject material of the day or to improve her level of understanding is supposed to endorse mastery-approach goals, while a student who aims at outperforming her peers is supposed to pursue performance-approach goals. Accordingly, a student who aims at avoiding being worse than his or her classmates is said to adopt performance-avoidance goals.

Research has shown that mastery-approach goals are the most consistent and reliable predictors of a wide range of desired outcomes including, but not limited to, interest (Hulleman et al., 2010), enjoyment (Daniels et al., 2009), and challenge seeking (Lee \& Kim, 2014). In contrast, performance-avoidance goals have been associated with undesired outcomes such as heightened anxiety (Daniels et al., 2009) and challenge avoidance (Jagacinski, Kumar, \& Kokkinou, 2008; Shim \& Ryan, 2005). Performance-approach goals have shown a mixed pattern. Some studies for instance have found that they did not differ from mastery-approach goals in outcomes such as task involvement and enjoyment among achievement oriented people (Elliot \& Harackiewicz, 1994). Other studies have also shown that although performance-approach goals are not associated with some positive outcomes such as intrinsic motivation (Murayama \& Elliot, 2009) and challenge seeking (Lee \& Kim, 2014), they predict academic performance (Barron \& Harackiewicz, 2003; Wolters, 2004).

Regarding the main aim of our study, the relation of mastery-approach goals and performance-approach goals to school performance, recent literature has revealed that performance-approach goals that are defined as a pure aim to outperform others, rather than as an overarching reason to demonstrate high competence (Elliot, 2005; cf. Kaplan \& Maehr, 2007), predict in a more reliable way academic performance, than mastery-approach goals (Bipp \& van Dam, 2014; Durik, Lovejoy, \& Johnson, 2009; Elliot, McGregor, \& Gable, 1999). These findings are consistent with the meta-analysis of Hulleman et al. (2010) but contradict a more recent meta-analysis which has shown that situationally induced mastery-approach goals, as compared to performance-approach ones, lead to somewhat better performance in verbal tasks (Van Yperen, Blaga, \& Postmes, 2015).

Regarding school performance, there are also a few studies which have shown that school performance is predicted either by both mastery-approach and performance-approach goals (Chen, 2015; Church, Elliot, \& Gable, 2001; Linnenbrink, 2005; Matos, Lens, Vansteenkiste, \& Mouratidis, 2017 - Sample 2; Niepel, Brunner, \& Preckel, 2014; Senko, Hama, \& Belmonte, 2013; Song, Bong, Lee, \& Kim, 2015) or by masteryapproach goals only (Keys, Conley, Duncan, \& Domina, 2012; Lau \& Nie, 2008; Matos et al., 2017 - Sample 1; Shim, Ryan, \& Anderson, 2008). Yet, most of these studies showing mastery-approach goals being equivalent or superior to performance-approach goals relied on an earlier conceptualization of performance-approach goals according to which the aim of outperforming others is intertwined with ego concerns - for instance the higher-order aim to demonstrate superior ability (see also Kaplan \& Maehr, 2007). Therefore, it remains unclear whether mastery-approach goals are more conducive than performance- approach goals when goals are devoid of a higher-order reason (e.g., to develop competence for mastery-approach goals; to demonstrate competence for performance-approach goals).

Indeed, research has shown that when performance-approach goals are operationally defined as pure aims (i.e., just to outperform others), they predict school performance in a more consistent way than masteryapproach goals do (Hulleman et al., 2010; Senko et al., 2011). Does this mean that students should favor performance-approach goals over mastery-approach goals if they are to achieve academically? Should they become more vigilant only on what is required to learn (Senko et al., 2013) thereby following the teachers' agenda (Hulleman \& Senko, 2010)? Not at all, because mastery-approach goals may still lead to improved academic performance. But they may do so in an indirect way. In support of this view, a few studies with university students have shown that mastery-approach goals predict, next to performance-approach goals, higher grades through interest (Harackiewicz, Durik, Barron, Linnenbrink-Garcia, \& Tauer, 2008) or enjoyment (Daniels et al., 2009).

Yet, as this brief overview of studies that operationally defined achievement goals as pure aims suggests, the indirect paths linking mastery-approach goals with academic performance have been shown in studies conducted in higher-education contexts and among university students. So, a question that awaits answering is whether a similar path exist in secondary educational systems, where interest, enjoyment, or challenge is less likely to manifest in courses, like mathematics, that are compulsory rather than elective. To the best of our knowledge, there has been only one study which investigated a similar process among high school students and which has also shown through path analysis mastery-approach goals to predict higher grades through interest (Dinger, Dickhauser, Spinath, \& Steinmayr, 2013). Yet, in that research the effects of prior grades were not considered. We therefore intended to revisit this issue by controlling for prior grades, by assessing performance-approach goals as well as mastery-approach and performance-avoidance goals as pure aims, and by examining challenge seeking as a particular mechanism that mediates the relation between mastery-approach (but not performance-approach or performanceavoidance goals) and school performance.

\subsection{Challenge seeking and achievement goals}

As said, challenge seeking constitutes an adaptive motivational response pattern (Dweck \& Leggett, 1988), namely because it is inherently tied with intrinsic motivation (Lepper, Corpus, \& Iyengar, 2005). Indeed, students who enjoy challenges (or perceive academic tasks as such) are more likely to recruit their inner resources and invest more time and effort in their schoolwork (Putwain et al., 2016; Strati, Schmidt, \& Maier, 2017). Besides, as Grant and Dweck (2003) have shown, seeking challenging tasks and striving for learning are closely associated to each other and they together predict more energy expenditure and persistence in class work (see also Donnellan, 2008). Apparently, such an adaptive response pattern is presumed to facilitate performance in the long run (Dettmers, Trautwein, Lüdtke, Kunter, \& Baumert, 2010) because, among others, challenge seeking seems to coincide with deep strategy use, preference for difficult tasks, and taking action in the face of impediments (Turner, Thorpe, \& Meyer, 1998).

Further support to the view that challenge seeking may act as the link between mastery approach goals and school performance comes from the meta-analytic review conducted by Hulleman et al. (2010). These authors found that mastery-approach goals that in their operational definition embrace the notion of challenge seeking and (or) interest were more positively related to performance $(r=0.14)$ as compared to mastery-approach goals that focus on mastery and improvement $(r=0.05)$. This meta-analytic finding implies that challenge-seeking may perhaps drive part of the relation between masteryapproach goals and performance, something which becomes unnoticed 
once mastery-approach goals are defined, and assessed, as pure aims. That is, as goals simply aiming at mastering, learning, and understanding a task in hand (Elliot \& Murayama, 2008). Even under such conceptualization however, mastery-approach goals may still relate to higher academic achievement because, as Senko et al. (2011) argue, mastery-approach goals may activate one's curiosity or challenge. Therefore, although it seems that challenge seeking may mediate, and explain, the relation between mastery-approach goals and academic performance, there is no empirical research testifying this proposition. The main aim of our study thus was to test this hypothesis. Furthermore, we investigated whether perceptions of classroom environment (namely, the degree to which classroom environment favors mastery strivings or competition) may also account for any variance in the endorsement of mastery-approach, performance-approach, and performance-avoidance goals.

\subsection{Perceived classroom environment and achievement goals}

In the achievement goal research tradition, the learning environment of a classroom, termed goal structures (Ames, 1992), is considered to direct students toward endorsing certain achievement goals (Meece, Anderman, \& Anderman, 2006; Meece, Glienke, \& Burg, 2006). Perceived classroom goal structures have been usually discerned as those that promote learning, mastery, and improvement (and thus termed mastery goal structures), those that favor competition and rivalry among students (and thus termed performance-approach goal structures), and those that highlight avoiding doing mistakes and showing incompetence in front of the others (and thus termed performance-avoidance goal structures).

There is ample evidence in the literature to claim that mastery goal structures are linked with more desired outcomes than performance goal structures (for a review, see Rolland, 2012). For instance, perceived mastery goal structures have been associated positively with intrinsic motivation (Murayama \& Elliot, 2009), help-seeking (Schenke, Lam, Conley, \& Karabenick, 2015), cognitive strategies (Wolters, 2004), and academic achievement (Lau \& Nie, 2008; Roseth, Johnson, \& Johnson, 2008), either directly, or indirectly through the endorsement of mastery-approach goals (Kaplan \& Maehr, 2007; Wolters, 2004). Conversely, performance-approach goal structures have been associated negatively with certain desired outcomes such as intrinsic motivation (Murayama \& Elliot, 2009), achievement, and task engagement and positively with some unwanted outcomes such as effort withdrawal and avoidance coping (Lau \& Nie, 2008). Yet, with respect to achievement, a quasi-experimental study showed that students performed better when they were found in classrooms in which more emphasis was put on performance-approach goals or on performanceapproach goals along with mastery-approach goals (Linnenbrink, 2005).

To summarize, the link between perceived goal structures and academic correlates has been shown through three different, sometimes overlapping, approaches. The first considers perceived goal structures, along with achievement goals, as antecedents of the school-related outcomes. The second approach presumes that goal structures enhance the adoption of certain achievement goals which in turn predict academic outcomes, whereas the third one investigates whether goal structures (namely as a classroom characteristic) moderate the association between personally endorsed achievement goals and outcomes (for an overview, see Murayama \& Elliot, 2009). In this study, we also examined whether perceived goal structures would relate to grades through the endorsement of the respective achievement goals and, in turn, through challenge-seeking. In doing so, we aimed to contribute as well to the discussion of whether perceived goal structures predict educational outcomes because they favor certain achievement goals (Meece et al., 2006), without ignoring however the reciprocal relation between perceived goal structure and achievement goals (as one's personal achievement goals may lead one to pay more attention to those environmental cues that confirm and validate the pursuit of these goals) (Nickerson, 1998). We avoided examining whether goal structures would moderate the association between achievement goals and grades as such a test would have required multilevel analyses. Yet, this analysis was not feasible because of the limited number of available classes (Hox, 2010).

\subsection{Overview of the present research}

In this study, our main aim was to investigate to what extent academic achievement would be explained through two different channels - a direct one that entails endorsing performance-approach goals (something which has been already shown in prior research, yet mainly with university students), and an indirect one that involves challenge seeking as a mediating mechanism linking mastery-approach goals to academic achievement. We focused on challenge seeking as a likely mediator of the relation between mastery-approach goals and higher grades for three reasons. First, because challenge seeking is by itself a desired educational outcome that reflects adaptive motivational processes (Dweck, 1986). Second because several studies have shown that challenge seeking predict higher grades (Lepper et al., 2005). Third, because in the earlier conceptualization of mastery-approach goals where challenge seeking was inherently tied with mastery-approach goals as an underlying reason (e.g., "It is very important to me to feel that my coursework offers me real challenges"), mastery-approach goals were found to predict academic performance (Grant \& Dweck, 2003; see also Hulleman et al., 2010).

To this direction and in line with the call of Senko et al. (2011), we hypothesized that challenge seeking would act as a mediator between mastery-approach goals and end-year grades even after we controlled for mid-semester grades (Hypothesis 1). Further, in line with the revised achievement goal theory which (a) operationally defines performance-approach goals as aims for surpassing others which are not necessarily tied with ego concerns (Elliot, 2005), and which (b) has shown that such kind of goals predict better academic performance (Hulleman et al., 2010), we anticipated performance-approach goals to directly predict higher grades, even after controlling for baseline grades (Hypothesis 2). Regarding performance-avoidance goals, we expected, in line with prior studies which have highlighted their maladaptive nature (Jagacinski et al., 2008; Shim \& Ryan, 2005), to relate negatively to challenge seeking and grades (Hypothesis 3 ).

Moreover, we explored whether perceived goals structures would predict higher grades and challenge seeking either directly or indirectly through achievement goals (Research Question 1). Irrespective of whether achievement goals would fully, partly, or do not mediate the relation between perceived goal structures and educational outcomes, we anticipated perceived mastery goal structures to relate positively to mastery-approach goals (Hypothesis 4a) and perceived performance goal structures to relate positively to both performance-approach and performance-avoidance goals (Hypothesis $4 \mathrm{~b}$ ). This is because literature has indicated that the achievement goals that a teacher is perceived to emphasize in his or her classroom are more easily adopted by the students (Meece et al., 2006).

To examine our hypotheses, we recruited a sample of Turkish high school students and focused on the math class. In doing so, we could examine the associations among perceived goal structures, personal achievement goals, and grades in a hypercompetitive context, given that the Turkish educational system is normatively selective. Many Turkish middle school students aspire to achieve high to be admitted to renowned high schools (through national exams) and the same is true for high school students who aspire to enter University because tertiary education, as compared to non-tertiary education, offers much more job opportunities in Turkey (OECD, 2012). The math course was chosen as it is one of the main subject matters that students are tested to enter University. 


\section{Method}

\subsection{Participants and procedures}

This study was part of a larger longitudinal research project, funded by the National Research Council in Turkey (TUBITAK). The study was approved by the Turkish Ministry of Education and by the ethical review board of the host University and was in accordance with the ethical treatment of human subjects. An approval to visit the selected schools, all located in the district of Ankara, was granted by the Ministry of Education, the school principals and school counselors, and the board of teachers. Also, prior to data collection, an informed consent was collected from students' parents. Participants were 369 (181 males; 178 females; 10 students omitted reporting their gender) high school students belonging to 18 intact classrooms in three high schools, all located in a district of average socioeconomic status in the city of Ankara. Students attended the 10th $(N=217), 11$ th $(N=215)$ and 12 th grade $(N=15)$ and their mean age was 16.67 years $(S D=1.85$; age range: $15-18$ years).

According to the available statistics provided by the Turkish Statistical Institute (2017), 52 students were coming from families with relatively low family income (i.e., less than $\$ 650$ per month), 199 from families with medium family income (i.e., between $\$ 650$ and $\$ 1650$ per month), and 107 from families with relatively high family income (i.e., > \$1600 per month); 11 students omitted this information. As for students' mothers, 56 (14.4\%) of them finished primary school, 168 had graduated from middle or high school, while 138 had either college, university or higher degree; the respective figures for students' fathers were 30,121 , and 208 (no information was provided for 7 mothers and 10 fathers).

To collect the data, three research assistants visited each of the three schools in three different days in the end of March and the first days of April of 2015. The research assistants delivered the questionnaires in class groups during a regular math class hour. Before doing that, they briefly explained to the students the purpose of the study (as said to them, the aim was to uncover the reasons students study mathematics). Also, they explained to the students that their participation was voluntary, that their responses would remain anonymous and confidential, and that there were no right or wrong answers. Only a few students $(<10)$ denied participation. All the questions were referred to mathematics, translated and back-translated by two independent groups according to the standards described by Hambleton and De Jong (2003), and presented on a five-point Likert-type format ( 1 = Strongly disagree; $5=$ Strongly agree). A few months later, (September of the next school year), a research assistant visited the schools anew to obtain students' grades in mathematics (both mid-year and end-year grades). The information regarding students' grades was provided from the math teachers.

\subsection{Measures}

\subsubsection{Perceived classroom goal structure scale}

Seven items that were adapted from the Patterns of Adaptive Learning Scale (PALS; Midgley et al., 2000) and from Urdan (2004) were used to gauge students' perception of whether the motivational environment of their math class favored mastery and learning (4 items; e.g., "In our math class, it's important to understand the exercises, not just memorize them"; $\alpha=0.87$ ) or competition ( 3 items; e.g., "In our math class, getting good grades is the main goal"; $\alpha=0.74$ )

\subsubsection{Achievement goals}

Three pairs of items from the Achievement Goal QuestionnaireRevised (Elliot \& Murayama, 2008) were used to assess students' mastery-approach goals, that is, the degree to which students aim at learning and improving ("My aim is to completely master the material presented in math class" and "My goal is to learn as much as possible in math class"; $\alpha=0.77$ ); performance-approach goals, that is, the degree to which students aim at outperforming others ("My goal is to perform better than the other students in math class." and "I am striving to do well compared to other students in math class."; $\alpha=0.83$ ); and performance-avoidance goals, that is, the degree to which students avoid being worse than others ("My aim is to avoid doing worse than other students" and "I am striving to avoid performing worse than others."; $\alpha=0.93)$.

\subsubsection{Challenge seeking}

Challenge for studying, a subscale from Motivation for Reading Questionnaire developed by Baker and Wigfield (1999), was adapted to measure students' preference for challenging tasks and exercises in mathematics. An example item reads, "I like hard, challenging math problems", and the internal consistency of this five-item subscale was $\alpha=0.88$.

\subsubsection{Grades}

Students' math grades in the mid and end of the school year obtained a few months later, were recorded. According to the grading system in Turkish high schools, grades range from 0 to 100 and the passing threshold is at 50 .

\subsection{Plan of analyses}

We analyzed our data in three steps. The first step concerned preliminary analyses, and included inspection of the descriptive statistics and whether some of the covariates - namely, students' gender, and grade-level as well as parents' education level and family income, would be correlated to the main variables. In the second step, which involved our main analyses, we tested the main hypotheses through path analysis, with the aid of $R$ and lavaan software package (Rosseel, 2012). Preliminary analyses in that step showed that the model would not converge unless we transformed the grades to a metric similar to those of the other scales. Therefore, grade scores were divided by 20 . Finally, in the third step we examined in more detail through bootstrap analysis (MacKinnon, Lockwood, Hoffman, West, \& Sheets, 2002) with 10,000 replications the main hypothesis of our study; that is, whether challenge seeking would indeed mediate the relation between masteryapproach goals and grades. These mediation tests were conducted through two different, yet complementary approaches. The first one was done within the framework of path modeling to test the indirect effects between mastery-approach goals and grades by means of challenge seeking; the second approach involved testing the same mediation through regressions with the aid of the macro syntax provided by Preacher and Hayes (2004). In those regressions, all the variables that were included in the path model were included as covariates. Finally, all the above tests were conducted in a stepwise fashion, first without and then after controlling for mid-year grades.

\section{Results}

\subsection{Preliminary analyses}

Preliminary analyses indicated significant differences in the linear combination of the measured variables as a function of gender (Wilk's $\Lambda=0.828, F[8,277]=7.17, p<0.01$, multivariate $\left.\eta^{2}=0.17\right)$ and grade level (Wilk's $\Lambda=0.944, F[8,277]=2.06, p<0.040$ ), but not as a function of parents' education (Wilk's $\Lambda=0.937, F[16,554]$ $=1.15, p=0.31$ ) or family income (Wilk's $\Lambda=0.951, F[16,554]$ $=0.88, p=0.59$ ). Inspection of the bivariate correlations however suggested that three out of the four covariates were related to one or more of the studied variables. Therefore, all the four covariates (i.e., gender, grade-level, parents' education, and family income) were included as covariates in all the subsequent analyses. Table 1 also shows that the two perceived goal structures and the three achievement goals 
Table 1

Descriptive statistics and zero-order correlations among the measured variables $(N=369)$.

\begin{tabular}{|c|c|c|c|c|c|c|c|c|c|c|c|c|c|c|}
\hline Variables & $M$ & $S D$ & 1 & 2 & 3 & 4 & 5 & 6 & 7 & 8 & 9 & 10 & 11 & 12 \\
\hline 1. Gender (Males vs. females) & 0.50 & 0.50 & - & & & & & & & & & & & \\
\hline 2. Grade-level (10 vs. $11 \& 12$ grade) & 0.47 & 0.50 & -0.04 & - & & & & & & & & & & \\
\hline 3. Parents' education level & 1.49 & 0.67 & -0.04 & $-0.18^{* * *}$ & - & & & & & & & & & \\
\hline 4. Family income & 1.15 & 0.65 & -0.09 & -0.09 & $0.42^{* *}$ & - & & & & & & & & \\
\hline 5. Perceived Map goal structures & 3.77 & 0.85 & $0.20^{* *}$ & -0.09 & $0.14^{* * *}$ & -0.04 & - & & & & & & & \\
\hline 6. Perceived Pap goal structures & 3.37 & 0.93 & $0.11^{*}$ & $-0.12^{* *}$ & 0.10 & -0.05 & $0.59 * *$ & - & & & & & & \\
\hline 7. Mastery-approach goals & 3.52 & 1.04 & $0.16^{* *}$ & $-0.12^{* *}$ & $0.21^{* *}$ & 0.02 & $0.51^{* *}$ & $0.25^{* *}$ & - & & & & & \\
\hline 8. Performance-approach goals & 3.35 & 1.14 & $0.21^{* *}$ & -0.04 & $0.14^{* * *}$ & -0.01 & $0.40^{* *}$ & $0.36^{* *}$ & $0.56^{* *}$ & - & & & & \\
\hline 9. Performance-avoidance goals & 3.25 & 1.07 & $0.13^{*}$ & $-0.13^{*}$ & 0.09 & -0.05 & $0.30^{* *}$ & $0.30^{* *}$ & $0.45^{* *}$ & $0.62^{* *}$ & - & & & \\
\hline 10. Challenge seeking in mathematics & 3.16 & 1.03 & $0.20^{* *}$ & -0.01 & $0.13^{*}$ & 0.01 & $0.40^{* *}$ & $0.16^{* *}$ & $0.53^{* *}$ & $0.33^{* *}$ & $0.18^{* *}$ & - & & \\
\hline 11. Mid-year grades in mathematics & 61.16 & 20.18 & $0.38^{* *}$ & -0.02 & 0.06 & -0.05 & $0.26^{* *}$ & 0.09 & $0.41^{* *}$ & $0.32^{* *}$ & $0.20^{* *}$ & $0.45^{* *}$ & - & \\
\hline 12. End-year grades in mathematics & 66.29 & 18.51 & $0.29^{* *}$ & 0.10 & 0.01 & -0.02 & $0.24^{* *}$ & 0.07 & $0.41^{* *}$ & $0.40^{* *}$ & $0.21^{* *}$ & $0.45^{* *}$ & $0.81^{* *}$ & - \\
\hline
\end{tabular}

Two-tailed; Map = Mastery-approach; Pap = Performance-approach .

${ }^{*} p<0.05$.

${ }^{* * *} p<0.01$.

were positively correlated to each other and they were all positively related to challenge seeking; also, all but perceived performance goal structures were positively related to grades.

\subsection{Path analyses}

Before testing our hypotheses, we first addressed our research question by examining whether achievement goals would fully, partly, or do not mediate the relation between perceived goal structures and challenge seeking as well as end-year math grades, after controlling for background variables and mid-year math grades. To address the mediation hypotheses, we pitted three main models to each other and found that a partial mediation model where perceived mastery goal structures were also directly linked with challenge-seeking best fitted our data and was more parsimonious as compared to the full-mediation model and the no-mediation model (where perceived goal structures and achievement goals lie at the same level and predict challenge seeking and grades). The partial mediation model (with students' gender and grade-level, as well as parents' education level and family income included as covariates) yielded the following fit: $S-B \chi^{2}(9, N=291)$ $=16.96, p=0.049$, CFI $=0.987$, SRMR $=0.027$, RMSEA $=0.055$ (90\% CI: 0.012-0.092). The fit indices of the competing models can be inspected in the supplementary file that is available online.

The model is displayed in Fig. 1 (covariates are not shown for reasons of parsimony). As can be noticed, there were two distinct paths linking perceived goal structures and achievement goals to grades.
Specifically, in line with Hypothesis 1, mastery-approach goals were positively related to challenge seeking which in turn positively predicted math grades. Also, in support of Hypothesis 2, performance-approach goals directly and positively predicted math grades, whereas in partial support of Hypothesis 3 performance-avoidance goals were negatively related to challenge seeking.

As explained also above, a multilevel structural equation modeling was not possible because of the few numbers of classes with respect to the estimated parameters. However, a imple multilevel path model that we ran as supplementary analysis showed, consistent to the main results, that both challenge seeking $(\beta=0.30, p=0.01)$ and performance-approach goals $(\beta=0.27, p<0.01$ ) were positive predictors of final grades.

Moving from the relation between achievement goal and outcomes to the relation between perceived goal structures and achievement goals, our tested model indicated perceived mastery goal structures to relate positively only to mastery-approach goals, and perceived performance goal structures to relate positively to both performance-approach and performance-avoidance goals; these findings provide support to Hypothesis $4 \mathrm{a}$ and $4 \mathrm{~b}$, respectively. Also, perceived mastery goal structures were directly associated with challenge seeking. Regarding the covariates (not shown in Fig. 1), some gender differences were found. Specifically, females perceived the climate of their classroom as more mastery-oriented ( $\beta=0.17, p<0.01$ ), scored higher in performance-approach goals $(\beta=0.18, p<0.01)$, reported higher levels of challenge seeking $(\beta=0.16, p<0.01)$, and had higher grades

Time 1

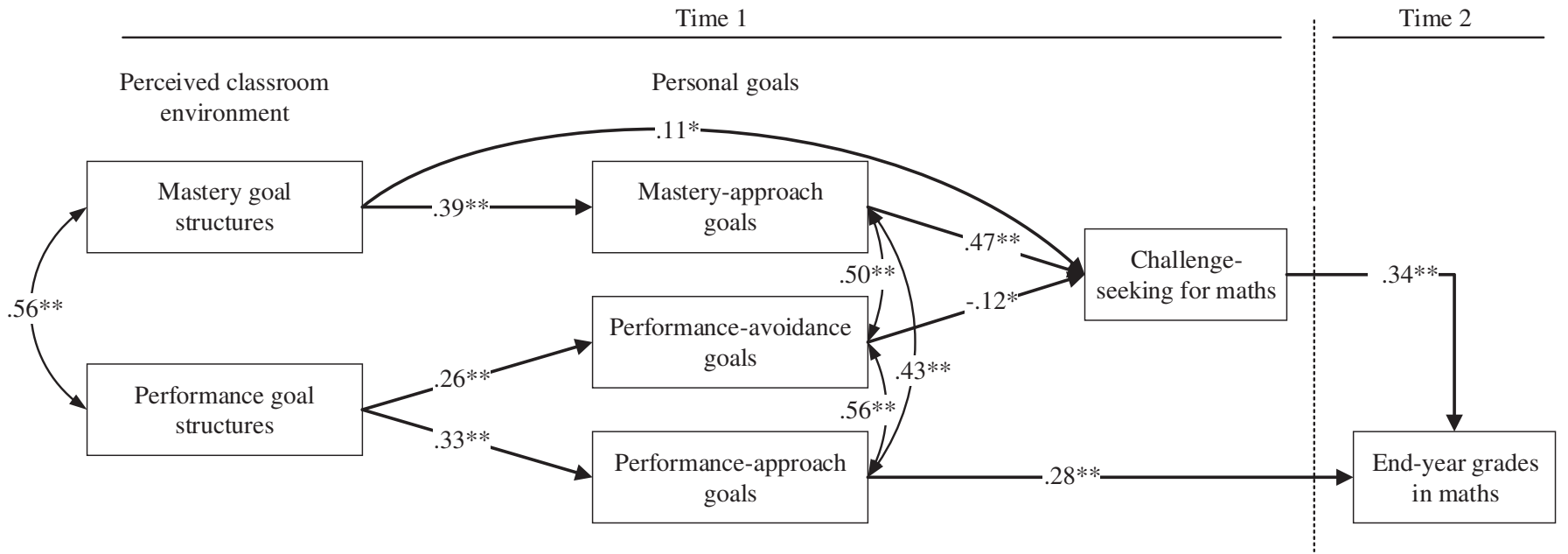

Fig. 1. Grades and challenge seeking in mathematics as predicted by perceived classroom environment and personal achievement goals. All path coefficients are standardized. Note. ${ }^{*} p<0.05$. $* * p<0.01$. 
$(\beta=0.16, p<0.01)$ than males. Also, parents' education was positively associated with students' mastery-approach goals $(\beta=0.14$, $p=0.017$ ).

Notably, all the above main paths remained statistically significant in a model where we controlled as well for mid-year grades: $S-B \chi^{2}(10$, $N=291)=18.60, \quad p=0.046, \quad$ CFI $=0.991, \quad$ SRMR $=0.032$, RMSEA $=0.054$ (90\% CI: $0.014-0.089$ ). (In that model, females outperform males in mid-year grades; $\beta=0.38, p<0.01$ ). More important, after controlling for mid-year grades $(\beta=0.75, p<0.01)$, both performance-approach goals $(\beta=0.16, p<0.01)$ and challenge seeking $(\beta=0.09, p<0.01)$ remained positive predictors of final grades. Also, both predictors remained statistically significant (respectively, $\beta=0.08, p=0.022$ and $\beta=0.18, p<0.01$ ), even when we controlled for mid-year grades $(\beta=0.71, p<0.01)$ in a simple multilevel path model.

\subsection{Test of indirect effects and mediation tests}

The test of indirect effects showed that mastery-approach goals indirectly and positively predicted end-year grades via challenge seeking ( $\beta=0.16, p<0.01$ ), whereas the opposite was true for performanceavoidance goals $(\beta=-0.04, p=0.048)$. Also, perceived mastery goal structures were indirectly linked with challenge seeking via masteryapproach goals $(\beta=0.19, p<0.01)$ and with end-year grades (via mastery-approach goals and, in sequence, via challenge seeking) $(\beta=0.06, p<0.01)$. Regarding perceived performance goal structures, these were indirectly and positively associated with end-year grades (by means of performance-approach goals $[\beta=0.10$, $p<0.01]$ ) but not with challenge seeking (by means of performanceavoidance goals $[\beta=-0.03, p=0.079]$ ).

Furthermore, in the path model where we controlled for mid-year grades, the indirect path linking mastery-approach goals with final grades by means of challenge seeking was also statistically significant $(\beta=0.04, p<0.01)$. Taken together, the latter path model with midyear grades serving as covariate, revealed that mastery-approach and performance-approach goals positively predicted changes in grades, the former indirectly through challenge seeking and the latter directly. In addition, the indirect path between perceived mastery goal structures and end-year grades by means of mastery-approach goals, and then by means of challenge seeking was also statistically significant $(\beta=0.02$, $p=0.015$ ). The same was true for the path linking perceived performance goal structures and end-year grades by means of performanceapproach goals $(\beta=0.06, p<0.01)$, but not by means of performance-avoidance goals and challenge seeking $(\beta=0.00, p>0.05)$. These findings imply that perceived mastery goal structures were more reliable predictors of academic performance than perceived performance goal structures, as the latter predicted academic performance only when students endorse performance-approach goals.

Moreover, the bootstrap approach within the framework of path analysis revealed that the mean value of the indirect relation between mastery-approach goals and end-year grades through challenge seeking remained statistically significant $(B=0.15, S E=0.03, z=4.76$, $p<0.01 ; \beta=0.16$ ), with its $95 \%$ confidence interval $(C I)$ lying between 0.09 and 0.22 . A similar finding was obtained in the model where mid-year grades were also taken into account $(B=0.04$, $S E=0.02, z=2.56, p=0.011 ; 95 \%-C I: 0.01-0.07 ; \beta=0.04)$.

Similar results were obtained when the same mediation hypothesis was tested through the regression analytical approach suggested by Hayes (2013). In particular, the bootstrap analysis for the mediation model revealed that the indirect relation between mastery-approach goals and end-year grades through challenge-seeking was positive $(B=2.22, S E=0.62 ; 95 \%-C I: 1.20-3.66)$. This relation remained positive, even when mid-year grades were also considered $(B=0.54$, $S E=0.29$; 95\%-CI: 0.06-1.19). These mediation analyses as well as those that examine the mediating role of achievement goals and challenge seeking in the relation between perceived goal structures and end-year grades can be found in the supplementary file that is available online. In sum, these findings provide some evidence that challenge seeking may lie between mastery-approach goals and school performance.

\section{Discussion}

In this study we investigated, after controlling for mid-semester grades in mathematics (as well as students' gender, grade-level and their parents' education level and family income), whether end-year grades in that mathematics can be predicted through two distinct routes, the one entailing the promotion and endorsement of masteryapproach goals and the other involving the promotion and endorsement of performance-approach goals. Our findings indicate, in agreement with Senko et al. (2011), that both mastery-approach and performanceapproach goals are conducive to academic performance, as reflected through grades. At first glance, it seems straightforward that performance-approach goals are more closely linked with academic performance. This finding, which is in line with similar previous ones (e.g., Harackiewicz, Barron, Tauer, Carter, \& Elliot, 2000), renders performance-approach goals quite appealing especially among students who aspire at succeeding in educational systems like the Turkish one where high-stakes testing in middle and high school determines one's admittance at specific high schools and universities, respectively.

Yet, unlike mastery-approach goals, performance-approach goals seem not to relate to a critical component of academic striving, which is challenge seeking. We view this lack of association as an evidence that performance-approach goals are less appealing compared to masteryapproach goals for three reasons. First, because challenge seeking should be considered a valuable outcome per se (Dweck, 1986) as it is inherently tied with feeling of enjoyment for goal-directed behaviors (Abuhamdeh \& Csikszentmihalyi, 2012). Second, because challenge seeking appears to protect students in the face of drawbacks (Meyer et al., 1997); and third, because it predicts higher grades too (see also Grant \& Dweck, 2003; Lepper et al., 2005). Thus, despite the presence of a "fast track road" that seems to link performance-approach goals with grades, the route that links mastery-approach goals with grades through challenge seeking seems more interesting and in line with the school-as-a-journey view (Kaplan \& Middleton, 2002), even in educational systems that might be normatively selective.

Another noteworthy finding concerns the relation of perceived goal structures to achievement goals and educational outcomes. Consistent with our expectations, perceived mastery goal structures were positively and uniquely associated with mastery-approach goals. This finding underscores the positive role that teachers may play in the educational process. In particular, it implies that the more teachers emphasize the value of learning and striving for mastery in their classes, the more their students endorse mastery-approach goals, seek challenges, and, eventually, succeed academically. In contrast, perceived performance goal structures were exclusively associated with both performance-approach goals (which were found to positively predict grades but not challenge seeking) and performance-avoidance goals (which were found to relate negatively to challenge seeking). Given this pattern of associations and the test of indirect effects which revealed that performance goal structures either negatively related or not related to challenge-seeking (respectively, via performance-avoidance and performance-approach goals), this finding underscores the potential benefits of promoting mastery goal even in math classrooms in educational systems in which high-stakes tests are unavoidable. It seems that establishing a mastery goal climate in the classroom is the best avenue for students to achieve academically and challenge themselves. It should be emphasized however that the relation between students' perceptions of the goal structures and their personal goals is reciprocal and cannot be ruled out that students' preference over certain goals may color their perceptions of the classroom goal structures (Nickerson, 1998; Nolen \& Haladyna, 1990). 
An issue which needs further discussion concerns the relation of performance-avoidance goals to challenge seeking and grades. Inspection of the bivariate correlations suggests that performanceavoidance goals were positively correlated to both. Nevertheless, a test of partial correlation revealed that the initially observed positive relation between performance-avoidance goals and challenge seeking turned from positive to negative once mastery-approach and performance-approach goals were taken into account $(r=-0.12$, $p=0.018$ ). A similar test revealed no relation between performanceavoidance goals and end-year math grades once mastery-approach goals, performance-approach goals, and mid-year grades were controlled for. These results apart from replicating previous ones that have shown performance-avoidance goals as the least fruitful goals (Elliot \& Church, 1997), underscore the necessity to concomitantly consider all the main achievement goals when examining their relation to educational outcomes as students may pursue multiple goals in the classroom (Pintrich, 2000). Such an examination could be made either under a variable-centered (e.g., multiple regression analysis) or a person-centered (e.g.., latent profile analysis) approach.

Regarding the observed gender differences (in particular, that females reported higher levels of mastery-approach goals and challenge seeking), these findings fit with recent studies showing females to report higher levels of intrinsic motivation (Bugler, McGeown, \& St ClairThompson, 2015) and mastery focus (Kenney-Benson, Pomerantz, Ryan, \& Patrick, 2006; Plenty \& Heubeck, 2013) than boys; however our findings contradict some other studies which have shown no gender differences among adolescent students (Yeung, Lau, \& Nie, 2011). Most likely, such differences in motivation may vary from sample to sample (Meece et al., 2006).

\subsection{Limitations}

There are several limitations in this research that should be noted. First, we cannot infer causality because the reported associations are based on correlational analyses. Therefore, regardless of whether data would have been collected in a single or multiple time points causality cannot be claimed because no manipulation took place. As we did not manipulate students' achievement goals, we cannot exclude the possibility for instance that students who are inclined to seek challenges in mathematics are more likely also to become gradually mastery oriented. Second, we disregarded the various reasons underlying the pursuit of achievement goals (Senko \& Tropiano, 2016; Vansteenkiste, Lens, Elliot, Soenens, \& Mouratidis, 2014), as research has shown that achievement goals may be pursued for different reasons. For instance, Darnon, Dompnier, Delmas, Pulfrey, and Butera (2009) have shown that students may pursue mastery goals to earn their teachers' appreciation (see also Michou, Vansteenkiste, Mouratidis, \& Lens, 2014), something which may predict students' grades. Therefore, future studies need to include the reasons underlying the pursuit of achievement goals when examining the mediating mechanisms linking mastery-approach goals with grades. Third, given the limited number of classes to which students were nested into, we did not employ multilevel analyses to examine to what extent class-level goal structures predict students' challenge seeking and grades (and whether they moderate the relation of achievement goals to these outcomes). Fourth, despite the good internal consistency that we obtained for the three achievement goals, we assessed each of them by means of two out of the three original items. Finally, we caution for generalization to other subject matters, educational systems, and population ages before similar studies test these findings in different educational settings.

\section{Conclusion}

From the achievement goal perspective, there seems to exist (at least) two different paths that may be associated with success: As our research suggests, though performance-approach goals seem to directly predict higher grades, mastery-approach goals can do so through challenge-seeking. Given that challenge seeking is a valuable outcome per se, and that perceived mastery goal structures, and in turn mastery goals endorsement, can also predict academic performance teachers will benefit students if they emphasize and praise mastery strivings in the classroom while they concurrently downplay competition.

\section{Acknowledgements}

We would like to thank the students for their participation as well and the principals the counselors and the teachers of the participating schools for their collaboration and support. We are also fully indebted to Aylin Koçak, Bariş Şahin, Özge Özgurt, and Bilgen Nur Yazici for their valuable contribution during data collection.

\section{Funding}

This work was supported by the Scientific and Technological Research Council of Turkey (TÜBITAK) [grant number 114K815].

\section{Appendix A. Supplementary data}

Supplementary data to this article can be found online at https:// doi.org/10.1016/j.lindif.2017.11.017.

\section{References}

Abuhamdeh, S., \& Csikszentmihalyi, M. (2012). The importance of challenge for the enjoyment of intrinsically motivated, goal-directed activities. Personality and Social Psychology Bulletin, 38, 317-330. http://dx.doi.org/10.1177/0146167211427147.

Ames, C. (1992). Clasrroms: Goals, structures, and student motivation. Journal of Educational Psychology, 84, 261-271. http://dx.doi.org/10.1037/0022-0663.84.3. 261.

Ames, C., \& Archer, J. (1988). Achievement goals in the classroom: Students' learning strategies and motivation processes. Journal of Educational Psychology, 80, 260-267. http://dx.doi.org/10.1037//0022-0663.80.3.260.

Baker, L., \& Wigfield, A. (1999). Dimensions of children's motivation for reading and their relations to reading activity and reading achievement. Reading Research Quarterly, 34, 452-477. http://dx.doi.org/10.1598/rrq.34.4.4.

Barron, K. E., \& Harackiewicz, J. M. (2003). Revisiting the benefits of performance-approach goals in the college classroom: Exploring the role of goals in advanced college courses. International Journal of Educational Research, 39, 357-374. http://dx.doi.org/ 10.1016/j.ijer.2004.06.004.

Bipp, T., \& van Dam, K. (2014). Extending hierarchical achievement motivation models: The role of motivational needs for achievement goals and academic performance. Personality and Individual Differences, 64, 157-162. http://dx.doi.org/10.1016/j.paid. 2014.02.039.

Brophy, J. (2005). Goal theorists should move on from performance goals. Educational Psychologist, 40, 167-176. http://dx.doi.org/10.1207/s15326985ep4003_3.

Bugler, M., McGeown, S. P., \& St Clair-Thompson, H. (2015). Gender differences in adolescents' academic motivation and classroom behaviour. Educational Psychology, 35, 541-556. http://dx.doi.org/10.1080/01443410.2013.849325.

Chen, W.-W. (2015). The relations between perceived parenting styles and academic achievement in Hong Kong: The mediating role of students' goal orientations. Learning and Individual Differences, 37, 48-54. http://dx.doi.org/10.1016/j.lindif. 2014.11.021.

Church, M. A., Elliot, A. J., \& Gable, S. L. (2001). Perceptions of classroom environment, achievement goals, and achievement outcomes. Journal of Educational Psychology, 93, 43-54. http://dx.doi.org/10.1037//0022-0663.93.1.43.

Daniels, L. M., Stupnisky, R. H., Pekrun, R., Haynes, T. L., Perry, R. P., \& Newall, N. E. (2009). A longitudinal analysis of achievement goals: From affective antecedents to emotional effects and achievement outcomes. Journal of Educational Psychology, 101, 948-963. http://dx.doi.org/10.1037/a0016096.

Darnon, C., Dompnier, B., Delmas, F., Pulfrey, C., \& Butera, F. (2009). Achievement goal promotion at university: Social desirability and social utility of mastery and performance goals. Journal of Personality and Social Psychology, 96, 119-134. http://dx.doi. org/10.1037/a0012824.

Dettmers, S., Trautwein, U., Lüdtke, O., Kunter, M., \& Baumert, J. (2010). Homework works if homework quality is high: Using multilevel modeling to predict the development of achievement in mathematics. Journal of Educational Psychology, 102, 467-482. http://dx.doi.org/10.1037/a0018453.

Dinger, F. C., Dickhauser, O., Spinath, B., \& Steinmayr, R. (2013). Antecedents and consequences of students' achievement goals: A mediation analysis. Learning and Individual Differences, 28, 90-101. http://dx.doi.org/10.1016/j.lindif.2013.09.005.

Donnellan, M. B. (2008). A psychometric evaluation of two achievement goal inventories. Educational and Psychological Measurement, 68, 643-658. http://dx.doi.org/10.1177/ 0013164407310125. 
Durik, A. M., Lovejoy, C. M., \& Johnson, S. J. (2009). A longitudinal study of achievement goals for college in general: Predicting cumulative GPA and diversity in course selection. Contemporary Educational Psychology, 34, 113-119. http://dx.doi.org/10. 1016/j.cedpsych.2008.11.002

Dweck, C. S. (1986). Motivational processes affecting learning. American Psychologist, 41, 1040-1048. http://dx.doi.org/10.1037//0003-066x.41.10.1040.

Dweck, C. S., \& Leggett, E. L. (1988). A social cognitive approach to motivation and personality. Psychological Review, 95, 256-273. http://dx.doi.org/10.1037//0033295x.95.2.256

Elliot, A. J. (2005). A conceptual history of the achievement goal construct. In A. J. Elliot, \& C. S. Dweck (Eds.). Handbook of competence and motivation (pp. 52-72). New York: Guilford.

Elliot, A. J., \& Church, M. A. (1997). A hierarchical model of approach and avoidance achievement motivation. Journal of Personality and Social Psychology, 72, 218-232. http://dx.doi.org/10.1037/0022-3514.72.1.218.

Elliot, A. J., \& Harackiewicz, J. M. (1994). Goal setting, achievement orientation, and intrinsic motivation: A mediational analysis. Journal of Personality and Social Psychology, 66, 968-980. http://dx.doi.org/10.1037/0022-3514.66.5.968.

Elliot, A. J., \& McGregor, H. A. (2001). A $2 \times 2$ achievement goal framework. Journal of Personality and Social Psychology, 80, 501-519. http://dx.doi.org/10.1037//00223514.80.3.501.

Elliot, A. J., McGregor, H. A., \& Gable, S. (1999). Achievement goals, study strategies, and exam performance: A mediational analysis. Journal of Educational Psychology, 91, 549-563. http://dx.doi.org/10.1037/0022-0663.91.3.549.

Elliot, A. J., \& Murayama, K. (2008). On the measurement of achievement goals: Critique, illustration, and application. Journal of Educational Psychology, 100, 613-628. http:// dx.doi.org/10.1037/0022-0663.100.3.613.

Grant, H., \& Dweck, C. S. (2003). Clarifying achievement goals and their impact. Journal of Personality and Social Psychology, 85, 541-553. http://dx.doi.org/10.1037/00223514.85.3.541.

Hambleton, R. K., \& De Jong, J. H. A. L. (2003). Advances in translating and adapting educational and psychological tests. Language Testing, 20, 127-134. http://dx.doi. org/10.1191/0265532203lt247xx.

Harackiewicz, J. M., Barron, K. E., Pintrich, P. R., Elliot, A. J., \& Thrash, T. M. (2002) Revision of achievement goal theory: Necessary and illuminating. Journal of Educational Psychology, 94, 638-645. http://dx.doi.org/10.1037//0022-0663.94.3. 638.

Harackiewicz, J. M., Barron, K. E., Tauer, J. M., Carter, S. M., \& Elliot, A. J. (2000). Shortterm and long-term consequences of achievement goals: Predicting interest and performance over time. Journal of Educational Psychology, 92, 316-330. http://dx.doi. org $/ 10.1037 / / 0022-0663.92 .2 .316$

Harackiewicz, J. M., Durik, A. M., Barron, K. E., Linnenbrink-Garcia, L., \& Tauer, J. M (2008). The role of achievement goals in the development of interest: Reciprocal relations between achievement goals, interest, and performance. Journal of Educational Psychology, 100, 105-122. http://dx.doi.org/10.1037/0022-0663.100.1. 105.

Hayes, A. F. (2013). Introduction to mediation, moderation, and conditional process analysis New York: Guilford.

Hox, J. (2010). Multilevel analysis: Techniques and applications (2nd ed.). Mahwah, NJ: Lawrence Erlbaum.

Hulleman, C. S., Schrager, S. M., Bodmann, S. M., \& Harackiewicz, J. M. (2010). A metaanalytic review of achievement goal measures: Different labels for the same constructs or different constructs with similar labels? Psychological Bulletin, 136, 422-449. http://dx.doi.org/10.1037/a0018947.

Hulleman, C. S., \& Senko, C (2010). Up around the bend: Forecasts for achievement goal theory and research in 2020. In T. C. Urdan, \& S. Karabenick (Vol. Eds.), Advances in motivation and achievement. vol. 16. Advances in motivation and achievement (pp. 71104). Bingley, UK: Emerald.

Jagacinski, C. M., Kumar, S., \& Kokkinou, I. (2008). Challenge seeking: The relationship of achievement goals to choice of task difficulty level in ego-involving and neutral conditions. Motivation and Emotion, 32, 310-322. http://dx.doi.org/10.1007/s11031 008-9103-3.

Kaplan, A., \& Maehr, M. L. (2007). The contributions and prospects of goal orientation theory. Educational Psychology Review, 19, 141-184. http://dx.doi.org/10.1007/ s10648-006-9012-5.

Kaplan, A., \& Middleton, M. J. (2002). Should childhood be a journey of a race? Response to Harackiewicz et al. (2002). Journal of Educational Psychology, 94, 646-648. http:// dx.doi.org/10.1037/0022-0663.94.3.646.

Kenney-Benson, G. A., Pomerantz, E. M., Ryan, A. M., \& Patrick, H. (2006). Sex differences in math performance: The role of children's approach to schoolwork. Developmental Psychology, 42, 11-26. http://dx.doi.org/10.1037/0012-1649.42.1.11.

Keys, T. D., Conley, A. M., Duncan, G. J., \& Domina, T. (2012). The role of goal orientations for adolescent mathematics achievement. Contemporary Educational Psychology, 37, 47-54. http://dx.doi.org/10.1016/j.cedpsych.2011.09.002.

Lau, S., \& Nie, Y. (2008). Interplay between personal goals and classroom goal structures in predicting student outcomes: A multilevel analysis of person-context interactions. Journal of Educational Psychology, 100, 15-29. http://dx.doi.org/10.1037/00220663.100.1.15

Lee, W., \& Kim, S. I. (2014). Effects of achievement goals on challenge seeking and feedback processing: Behavioral and fMRI evidence. PLoS One, 9. http://dx.doi.org/ 10.1371/journal.pone.0107254.

Lepper, M. R., Corpus, J. H., \& Iyengar, S. S. (2005). Intrinsic and extrinsic motivational orientations in the classroom: Age differences and academic correlates. Journal of Educational Psychology, 97, 184-196. http://dx.doi.org/10.1037/0022-0663.97.2. 184.

Linnenbrink, E. A. (2005). The dilemma of performance-approach goals: The use of multiple goal contexts to promote students' motivation and learning. Journal of Educational Psychology, 97, 197-213. http://dx.doi.org/10.1037/0022-0663.97.2. 197.

MacKinnon, D. P., Lockwood, C. M., Hoffman, J. M., West, S. G., \& Sheets, V. (2002). A comparison of methods to test mediation and other intervening variable effects. Psychological Methods, 7, 83-104. http://dx.doi.org/10.1037/1082-989X.7.1.83.

Matos, L., Lens, W., Vansteenkiste, M., \& Mouratidis, A. (2017). Optimal motivation in Peruvian high schools: Should learners pursue and teachers promote mastery goals, performance-approach goals or both? Learning and Individual Differences, 55, 87-96. http://dx.doi.org/10.1016/j.lindif.2017.02.003.

Meece, J. L., Anderman, E. M., \& Anderman, L. H. (2006). Classroom goal structure, student motivation, and academic achievement. Annual Review of Psychology, 57, 487-503. http://dx.doi.org/10.1146/annurev.psych.56.091103.070258.

Meece, J. L., Glienke, B. B., \& Burg, S. (2006). Gender and motivation. Journal of School Psychology, 44, 351-373. http://dx.doi.org/10.1016/j.jsp.2006.04.004.

Meyer, D. K., Turner, J. C., \& Spencer, C. A. (1997). Challenge in a mathematics classroom: Students' motivation and strategies in project-based learning. The Elementary School Journal, 97, 501-521. http://dx.doi.org/10.1086/461878.

Michou, A., Vansteenkiste, M., Mouratidis, A., \& Lens, W. (2014). Enriching the hierarchical model of achievement motivation: Autonomous and controlling reasons underlying achievement goals. British Journal of Educational Psychology, 84, 650-666.

Midgley, C., Kaplan, A., \& Middleton, M. (2001). Performance-approach goals: Good for what, for whom, under what circumstances, and at what cost? Journal of Educational Psychology, 93, 77-86. http://dx.doi.org/10.1037//0022-0663.93.1.77.

Midgley, C., Maehr, M. L., Hruda, L. Z., Anderman, E., Anderman, L. H., Freeman, E. C., .. Urdan, T. C. (2000). Manual for the patterns of adaptive Learcning scales. Ann Arbor, MI: University of Michigan.

Murayama, K., \& Elliot, A. J. (2009). The joint influence of personal achievement goals and classroom goal structures on achievement-relevant outcomes. Journal of Educational Psychology, 101, 432-447. http://dx.doi.org/10.1037/a0014221.

Nicholls, J. G. (1984). Achievement motivation: Conceptions of ability, subjective experience, task choice, and performance. Psychological Review, 91, 328-346. http://dx. doi.org/10.1037/0033-295x.91.3.328.

Nickerson, R. S. (1998). Confirmation bias: A ubiquitous phenomenon in many guises. Review of General Psychology, 2, 175-220. http://dx.doi.org/10.1037/1089-2680.2.2. 175.

Niepel, C., Brunner, M., \& Preckel, F. (2014). Achievement goals, academic self-concept, and school grades in mathematics: Longitudinal reciprocal relations in above average ability secondary school students. Contemporary Educational Psychology, 39, 301-313. http://dx.doi.org/10.1016/j.cedpsych.2014.07.002.

Nolen, S. B., \& Haladyna, T. M. (1990). Personal and environmental influences on students' beliefs about effective study strategies. Contemporary Educational Psychology, 15, 116-130. http://dx.doi.org/10.1016/0361-476X(90)90011-0.

OECD (2012). Equity and Quality in Education: Supporting Disadvantaged Students and Schools. Retrieved fromhttp://dx.doi.org/10.1787/9789264130852-en.

Pintrich, P. R. (2000). Multiple goals, multiple pathways: The role of goal orientation in learning and achievement. Journal of Educational Psychology, 92, 544-555. http://dx. doi.org/10.1037/0022-0663.92.3.544.

Plenty, S., \& Heubeck, B. G. (2013). A multidimensional analysis of changes in mathematics motivation and engagement during high school. Educational Psychology, 33, 14-30. http://dx.doi.org/10.1080/01443410.2012.740199.

Preacher, K. J., \& Hayes, A. F. (2004). SPSS and SAS procedures for estimating indirect effects in simple mediation models. Behavior Research Methods, Instruments, \& Computers, 36, 717-731. http://dx.doi.org/10.3758/Bf03206553.

Putwain, D. W., Nicholson, L. J., Nakhla, G., Reece, M., Porter, B., \& Liversidge, A. (2016) Fear appeals prior to a high-stakes examination can have a positive or negative impact on engagement depending on how the message is appraised. Contemporary Educational Psychology, 44, 21-31. http://dx.doi.org/10.1016/j.cedpsych.2015.12. 001.

Rolland, R. G. (2012). Synthesizing the evidence on classroom goal structures in middle and secondary schools: A meta-analysis and narrative review. Review of Educational Research, 82, 396-435. http://dx.doi.org/10.3102/0034654312464909.

Roseth, C. J., Johnson, D. W., \& Johnson, R. T. (2008). Promoting early adolescents' achievement and peer relationships: The effects of cooperative, competitive, and individualistic goal structures. Psychological Bulletin, 134, 223-246. http://dx.doi. org/10.1037/0033-2909.134.2.223.

Rosseel, Y. (2012). Lavaan: An R package for structural equation modeling. Journal of Statistical Software, 48, 1-36.

Schenke, K., Lam, A. C., Conley, A. M., \& Karabenick, S. A. (2015). Adolescents' help seeking in mathematics classrooms: Relations between achievement and perceived classroom environmental influences over one school year. Contemporary Educational Psychology, 41, 133-146. http://dx.doi.org/10.1016/j.cedpsych.2015.01.003.

Senko, C., Hama, H., \& Belmonte, K. (2013). Achievement goals, study strategies, and achievement: A test of the "learning agenda" framework. Learning and Individual Differences, 24, 1-10. http://dx.doi.org/10.1016/j.lindif.2012.11.003.

Senko, C., Hulleman, C. S., \& Harackiewicz, J. M. (2011). Achievement goal theory at the crossroads: Old controversies, current challenges, and new directions. Educational Psychologist, 46, 26-47. http://dx.doi.org/10.1080/00461520.2011.538646.

Senko, C., \& Tropiano, K. L. (2016). Comparing three models of achievement goals: Goal orientations, goal standards, and goal complexes. Journal of Educational Psychology, 108, 1178-1192. http://dx.doi.org/10.1037/edu0000114.

Shim, S., \& Ryan, A. (2005). Changes in self-efficacy, challenge avoidance, and intrinsic value in response to grades: The role of achievement goals. Journal of Experimental Education, 73, 333-349. http://dx.doi.org/10.3200/Jexe.73.4.333-349.

Shim, S. S., Ryan, A. M., \& Anderson, C. J. (2008). Achievement goals and achievement during early adolescence: Examining time-varying predictor and outcome variables 
in growth-curve analysis. Journal of Educational Psychology, 100, 655-671. http://dx. doi.org/10.1037/0022-0663.100.3.655.

Song, J., Bong, M., Lee, K., \& Kim, S.-i. (2015). Longitudinal investigation into the role of perceived social support in adolescents' academic motivation and achievement. Journal of Educational Psychology, 107, 821-841. http://dx.doi.org/10.1037/ edu0000016.

Strati, A. D., Schmidt, J. A., \& Maier, K. S. (2017). Perceived challenge, teacher support, and teacher obstruction as predictors of student engagement. Journal of Educational Psychology, 109, 131-147. https://doi.org/10.1037/edu0000108.

Turkish Statistical Institute (2017). Retrieved from http://www.turkstat.gov.tr/PreTablo. do?alt_id = 101 on November 06, 2017.

Turner, J. C., Thorpe, P. K., \& Meyer, D. K. (1998). Students' reports of motivation and negative affect: A theoretical and empirical analysis. Journal of Educational Psychology, 90, 758-771. http://dx.doi.org/10.1037/0022-0663.90.4.758.

Urdan, T. (2004). Predictors of academic self-handicapping and achievement: Examining achievement goals, classroom goal structures, and culture. Journal of Educational
Psychology, 96, 251-264. http://dx.doi.org/10.1037/0022-0663.96.2.251.

Van Yperen, N. W., Blaga, M., \& Postmes, T. (2015). A meta-analysis of the impact of situationally induced achievement goals on task performance. Human Performance, 28, 165-182. http://dx.doi.org/10.1080/08959285.2015.1006772.

Vansteenkiste, M., Lens, W., Elliot, A., Soenens, B., \& Mouratidis, A. (2014). Moving the achievement goal approach one step forward: Toward a systematic examination of the autonomous and controlled reasons underlying achievement goals. Educational Psychologist, 49, 153-174. http://dx.doi.org/10.1080/00461520.2014.928598.

Wolters, C. A. (2004). Advancing achievement goal theory: Using goal structures and goal orientations to predict students' motivation, cognition, and achievement. Journal of Educational Psychology, 96, 236-250. http://dx.doi.org/10.1037/0022-0663.96.2. 236.

Yeung, A. S., Lau, S., \& Nie, Y. (2011). Primary and secondary students' motivation in learning English: Grade and gender differences. Contemporary Educational Psychology, 36, 246-256. http://dx.doi.org/10.1016/j.cedpsych.2011.03.001. 